\title{
O campo de extermínio como paradigma do poder soberano na contemporaneidade
}

\section{Estenio Ericson Botelho de Azevedo, UECE}

Resumo: Em O que resta de Auschwitz, Agamben concebe um novo patamar da experiência biopolítica, em que o estado de exceção como norma traz consigo o "muçulmano" como figura exemplar. O que caracteriza a biopolítica na contemporaneidade para Agamben é menos a oposição, no sentido clássico, entre vida nua e forma de vida, ou ainda, a indistinção entre elas, própria ao moderno. O que o campo revela é que no homem pode haver uma cisão ainda mais profunda: nesta, a vida orgânica se isola da vida animal, produzindo-se assim uma mera existência destituída de humanidade. Esta é a figura do "muçulmano", na qual se constitui o apartamento do não-humano com relação ao humano. A partir da experiência dos campos de concentração (e extermínio), o biopoder é capaz de ultrapassar o limite da vida animal do homem ao produzir essa separação no interior da própria vida humana.

Palavras-chave: soberania; campo; muçulmano.

\author{
"Auschwitz" [...] é a prova, por assim \\ dizer, sempre viva de que o nomos (lei, \\ norma) do espaço político contemporâneo \\ - portanto, não só do espaço político \\ específico do regime nazista - não é mais \\ a bela (e idealizada) construção da cidade \\ comum (pólis), mas sim o campo de \\ concentração. \\ (Jeanne-Marie Gagnebin)
}

A experiência dos campos de concentração nazistas é para Agamben um dos paradigmas centrais da compreensão do que chama de experiência biopolítica moderna, considerando a imagem do muçulmano como aquela que se põe no limiar da própria existência biológica. Diz ele:

Ao lado dessa imagem biológica, põe-se imediatamente outra, que, aliás, parece conter o seu verdadeiro sentido. O mulçumano é não só, e nem tanto, um limite entre a vida e a morte; ele marca, muito mais, o limiar entre o homem e o não-homem. ${ }^{1}$

Pensada de modo detido, nessa imagem são postas em xeque as noções de homem e de humanidade que aparecem ali na reflexão de Vigiar e Punir como limites do exercício do poder sobre a vida. ${ }^{2}$ Se, segundo o pensador francês, a noção de humanidade apareceria ali como limite da aplicação da pena, que, se levada às últimas consequências, acarreteria a morte dos condenados, em Agamben a 
experiência do campo extrapola esta noção e produz uma zona de indiscernibilidade entre o homem e o não-homem: "Existe, portanto, um ponto em que, apesar de manter a aparência de homem, o homem deixa de ser humano. Esse ponto é o muçulmano, e o campo é, por excelência, o seu lugar". ${ }^{3}$ O deixar de ser humano expressa em Agamben a destituição de si daquela forma jurídica que os indivíduos assumem propriamente no período moderno. A forma da humanidade, a condição jurídica da dignidade que os homens assumem na era moderna, é aqui posta em questão e sua destituição é levada às últimas consequências.

Continuando aquela passagem citada, Agamben lança perguntas: "O que significa, porém, para um homem, tornar-se um não-homem? Existe uma humanidade do homem que se possa distinguir e separar da sua humanidade biológica?". ${ }^{4}$ Essas questões dirigem a análise do teórico de Homo Sacer numa obra na qual ele dialoga com autores como Primo Levi, Salmen Lewental, Bruno Bettelheim, que são testemunhas dessa experiência dos campos de concentração. Aliás, a própria compreensão da possibilidade de se testemunhar sobre tal experiência é então questionada, já que o portador legítimo dessa capacidade de dizer sobre não pode se colocar, contraditoriamente, na condição da fala: é ele o muçulmano, o limiar da vida biológica, da própria humanidade, o não-homem.

É esse olhar sobre o campo que, para Agamben, teria faltado a Foucault. O campo é, para o pensador italiano, o paradigma contemporâneo do poder, poder este que se manifesta, como aponta o pensador francês, como biopoder; não é a pena, mas a própria inexistência da pena diante de uma realidade em que o poder (violência) confunde-se com a própria ação sobre a vida. O campo é o não-lugar do direito, da norma, mas é, ao mesmo tempo, a experiência que torna possível que a não aplicabilidade da norma, do direito, torne-se norma, torne-se normal, seja enquadrada no âmbito do direito, que é aqui indiscernível com relação ao fato. E poderíamos ainda dizer: essa é uma experiência na qual, no limite, o próprio direito, a própria norma é posta em questão; e é igualmente, no limite, suspensa in toto. No campo, encontra-se não apenas a suspensão de toda forma política (bíos, a forma de vida que nas experiências clássica e moderna se opõe à vida nua, zoé), mas também a ruptura com aquilo que caracterizaria o homem como simplesmente vida, ultrapassando o que seria o próprio limiar do humano. E disso se produz um novo limiar: o muçulmano não é, e sobre isso não há dúvidas, uma vida politicamente qualificada, em sua conciliação com a vida nua; tampouco está simplesmente no patamar de uma mera vida, no sentido de ser apenas destituída de sua forma política. $\mathrm{O}$ muçulmano se encontra num espaço em que a própria existência meramente natural faz-se ultrapassada e se cinde internamente. E isso ocorre porque, segundo o pensador italiano, as "cesuras biológicas são, pois, essencialmente móveis e isolam, de cada vez, no continuum da vida, uma zona ulterior, que corresponde a um processo de Entwürdigung [aviltamento] e de degradação cada vez mais acentuado". 5

A extensão da dignidade a todos os homens constitui uma experiência propriamente moderna. É notável que na experiência do campo se produza um ser destituído de toda dignidade, de toda glória e que se manifesta como uma vida que extrapola até os limites de sua mera condição natural, biológica; uma existência cuja vida se desnuda a tal ponto que o próprio homem, posto diante dela, choca-se e se envergonha, mas nela se vê, pois essa condição aparece como potência de sua própria existência. O não-humano não é algo fora da potencialidade humana, mas é justamente aquilo a que, literalmente, o homem pode chegar, aquilo que pode ser

Cadernos Benjaminianos, Número especial, Belo Horizonte, 2013, página 77-88 
produzido pelo homem e que faz da sobrevivência o princípio constitutivo desse mesmo humano. E se o não-homem está fora da condição de humanidade, isso ocorre somente à medida que estabelece com ela uma relação de exceção - ou de abandono.

O muçulmano, o não-homem produzido por essa experiência, é, assim, a "substância biopolítica absoluta, que não pode ser determinada e nem pode [mais] admitir cesuras". ${ }^{6}$ É neste sentido que a imagem do muçulmano é apresentada por Agamben como o limiar da vida biológica, o ponto máximo a que pode chegar a cisão no interior do próprio humano; e esta não é outra coisa que a "cisão entre o orgânico e o animal”. Para Agamben, essa cisão

atravessa a vida inteira do indivíduo, ficando marcada pela oposição entre a continuidade das funções orgânicas (circulação do sangue, respiração, assimilação, excreção etc.) e a intermitência das funções animais (a mais evidente entre elas é a do sono-vigília), entre a assimetria da vida orgânica (um só estômago, um fígado, um coração) e a simetria da vida animal (um cérebro simétrico, dois olhos, duas orelhas, dois braços etc.) e, por último, na não coincidência entre seu início e o seu fim. Assim como, de fato, a vida orgânica começa no feto, antes do que a vida animal, assim também, no envelhecimento e na agonia, sobrevive à morte desta. ${ }^{7}$

Vida orgânica e vida animal: esta é a cisão a que chega a (bio)política. E nessa cisão, segundo aí se apresenta, a primeira é a que resta. A sobrevivência se manifesta nesses termos como um para-aquém da vida animal, ou ainda, para usarmos a expressão grega, um para-aquém da zoé. Até que ponto poder-se-ia então pensar essa forma orgânica da vida como humana, se ela está para aquém da própria vida animal?

\section{Auschwitz e a crise da dignidade moderna}

Auschwitz é a experiência que põe em xeque a noção moderna de humanidade e, com ela, também o significado de dignidade, tão caro aos juristas e canonistas e, de modo mais intenso, aos defensores dos direitos humanos. Extrapolam-se nela os limites de uma existência digna. Lá no campo, diz Agamben, "todos, de algum modo, haviam perdido a dignidade humana". ${ }^{8}$ E continua: "Talvez nunca, antes de Auschwitz, tenham sido descritos com tanta eficácia o naufrágio da dignidade perante uma figura extrema do humano e a inutilidade do respeito de si perante a absoluta degradação". ${ }^{9}$ Eis o patamar em que a vida e a norma (ainda que na forma da ausência e do abandono) se intercruzam e se indeterminam. Esvai-se não só a aplicabilidade normal da norma, mas com ela a própria possibilidade de uma experiência ética, de uma experiência mediada e controlada pelo direito: "Essa é precisamente a aporia ética específica de Auschwitz: é o lugar onde não é decente continuar sendo decente, onde os que ainda acreditam que conservam dignidade e respeito de si sentem vergonha dos que de imediato os haviam perdido"10.

Esta perda não é individual, mas aparece como produzida pela experiência propriamente humana, no sentido de humanidade, no sentido da política dirigida para tal pelo corpo social dessa humanidade. Se, na imagem do muçulmano, percebe-se até onde se pode chegar, isto é, ao não-lugar do humano, à total perda da dignidade, também nela se reflete a imagem de um outro, que estaria no extremo

Cadernos Benjaminianos, Número especial, Belo Horizonte, 2013, página 77-88 
oposto deste destituído de toda vida política: o humano. "O muçulmano é o nãohomem que se apresenta obstinadamente como homem, e o humano que é impossível dissociar do inumano". ${ }^{11}$ A existência humana, assim, está condicionada pela existência do não-humano. E este último não é senão o paradigma da humanidade. Muito mais do que oposições, essas instâncias expõem-se como elementos indiscerníveis de um mesmo ser. A imagem do não-humano, a sua vergonha, a sua miséria, é ela também a imagem do humano, de sua vergonha e de sua miséria.

Há, portanto, uma estreita relação entre esta produção do muçulmano pelo campo e a produção das outras experiências humanas, os outros indivíduos que compõem igualmente a realidade dos campos. Se bem considerado, percebe-se que, em Agamben, à medida que é produzido, o muçulmano expressa na sua autoimagem não apenas a condição de miséria da vida humana, indissociável de sua própria vida, mas que ela só o é como produto da própria humanidade, ainda que na figura do algoz ou do sobrevivente. Ao falar de suas vergonhas, os sobreviventes parecem deixar isto indicado: "o homem é aquele que pode sobreviver ao homem". ${ }^{12}$ É como se nesse processo de produção do não-humano o que resta se faz como humano. Por mais inconcebível que possa parecer essa realidade, ela se estabelece por meio dessa unidade, como se ela fosse a expressão de um avanço sobre os limites da humanidade. Mas quando isso ocorre, algo significativo igualmente vem à tona: o limite não é mais o mesmo, não é mais a mera vida, a vida nua, pensada simplesmente como uma vida destituída de sua forma política, mas, sim, um paraaquém dela, a vida orgânica dissociada da vida animal.

A vergonha seria menos uma imagem decadente da humanidade no seu sentido físico, biológico-natural, e mais uma imagem ascendente de uma humanidade que se apresenta distinta dessa primeira, mas que, na verdade, não pode ser pensada sem ela. A vergonha é precisamente a possibilidade de se perceber essa conexão. A ausência da vergonha, por outro lado, é a enganosa tentativa de ocultar o vínculo inquebrável entre o humano e o não-humano, o que inevitavelmente caracteriza, como caracterizou, as experiências como os fascismos alemão e italiano. Quando chega a esse ponto, a humanidade espelha, talvez da pior forma, a sua condição inumana ou, indistintamente, humana; daí a emergência da figura do sobrevivente, em seu plexo com a do muçulmano:

Essa indivisível partição, essa vida cindida e, mesmo assim, indissolúvel, se expressa por uma dupla sobrevivência: o não-homem é quem pode sobreviver ao homem, e o homem é quem pode sobreviver ao não-homem. Só porque a vida humana é essencialmente destrutível e divisível, a testemunha pode sobreviver-lhes. ${ }^{13}$

Mas a testemunha como sobrevivência não pode falar de outra experiência que não a sua. Ainda que, ao falar da sua experiência, inevitavelmente fale da outra, só se sabe o que é essa outra - a experiência do não-sobrevivente - pela relação que mantém com aquela. Primo Levi é um sobrevivente, a "testemunha perfeita" com quem Agamben mantém um diálogo privilegiado na sua exposição sobre Auschwitz. Apropriando-se das reflexões daquele, este então afirma sobre o significado filosófico da figura do muçulmano no campo de concentração:

o muçulmano é, antes, o lugar de um experimento, em que a própria moral, a própria humanidade são postas em questão. É uma figura-limite de uma

Cadernos Benjaminianos, Número especial, Belo Horizonte, 2013, página 77-88 
espécie particular, em que perdem sentido não só categorias como dignidade e respeito, mas até mesmo a própria ideia de um limite ético. ${ }^{14}$

Por isso ganha importância para Agamben uma reflexão sobre o significado que a categoria dignidade ganha no mundo moderno. Segundo ele, "a construção de uma verdadeira teoria da dignidade deve-se aos juristas e aos canonistas medievais". ${ }^{15}$ Por isso the são relevantes as análises de Kantorowicz. ${ }^{16}$ Segundo o pensador italiano, esse historiador alemão "mostrou como a ciência jurídica se vincula estreitamente com a teologia a fim de enunciar um dos pilares da teoria da soberania, o do caráter perpétuo do poder político". ${ }^{17}$ As reflexões de Kantorowicz são elucidativas à medida que elas nos possibilitam compreender o modo como, no dizer de Agamben, "A dignidade emancipa-se do seu portador e converte-se em pessoa fictícia, uma espécie de corpo místico que se põe junto do corpo real". ${ }^{18}$ A dignidade, portanto, constitui a mística do Estado político moderno. Ela é a figura que se coloca na base de uma relação identitária que os indivíduos assumem na modernidade. Diante de todas as distinções possíveis entre os humanos, uma coisa resta: sua dignidade, que quase se confunde com a própria imagem da humanidade, do povo posto como poder soberano. A dignidade é, nesses termos, a efígie do corpo social que deve ser guardada, velada, cuidada e, por que não dizer, amada, desejada e defendida por todos.

A dignidade, segundo a tese que Agamben elabora com base em suas leituras de Kantorowicz, não está, portanto, relacionada à dimensão mais imediata do homem em sua existência natural (corpórea ou anímica), mas, como se pode ver já em alguns pensadores modernos, ela é concebida em termos jurídicos; mesmo quando se pretende uma categoria ética, é representada numa distinção propriamente jurídica em face da condição natural do homem. Sua especificidade está em que, em sua originária condição jurídica, remeter-se-ia ao direito público. De fato, pelo menos desde a Renascença, com Pico della Mirandola, a ideia da dignidade humana é pensada sob a forma jurídica do direito público, e justamente quando se quer enfatizar, como é o caso desse filósofo italiano, que o homem deve "obter e possuir aquele lugar, aquele aspecto, aquela tarefa que desejar, tudo segundo o seu parecer e a sua decisão". Sendo de uma "natureza indefinida", o homem possui uma "grandeza" que se constitui em ser "árbitro e soberano artífice de si mesmo"; ${ }^{19}$ e por ser árbitro e soberano, é igualmente, e nesta medida, digno.

Mas, e é essa a grande questão ética contemporânea,

Auschwitz marca o fim e a ruína de qualquer ética da dignidade e da adequação a uma norma. A vida nua, a que o homem foi reduzido, não exige nem se adapta a nada: ela própria é a única norma, é absolutamente imanente. E "o sentimento último de pertencimento à espécie" não pode ser, em nenhum caso, uma dignidade. ${ }^{20}$

Eis então o paradigma do mundo contemporâneo: a colocação da vida como centro, mas ao mesmo tempo a produção da possibilidade de sua destituição, de sua destruição diante de sua confusão com a norma, na forma do abandono. Abandono não significa, nesse caso, simplesmente "deixar morrer", tampouco "fazer morrer", ${ }^{21}$ pois, como deixa claro Agamben,

Cadernos Benjaminianos, Número especial, Belo Horizonte, 2013, página 77-88 
Em Auschwitz não se morria: produziam-se cadáveres. Cadáveres sem morte, não-homens cujo falecimento foi rebaixado à produção em série. É precisamente a degradação da morte que constituiria, segundo uma possível e difundida interpretação, a ofensa específica de Auschwitz, o nome próprio de seu horror. ${ }^{22}$

Nesta realidade, não se trata apenas de uma condução do poder no sentido de fazer ou deixar morrer: a experiência do campo consegue romper com aquela questão propriamente foucaultiana a respeito da contradição posta para um poder que se funda no cuidado com a vida e que encontra seu limite quando pode também dar fim à vida.

Na figura do muçulmano, o poder, o biopoder, encontra então seu ponto de fuga: ele não se aplica contra a vida como seu sentido último, ele ultrapassa o limite da própria vida, ele produz um ser orgânico que não está vivo, mas que também não se apresenta como morto. Ele produz o limiar, o ponto de encontro e indistinção entre a vida e a morte: o muçulmano, que

não é mais do que o volkloser Raum, o espaço vazio de povo no centro do campo, que, ao separar toda vida de si mesmo, marca a passagem do cidadão para o Staatsangehörige de ascendência não ariana, do não ariano para o judeu, do judeu para o deportado e, finalmente, do deportado para além de si mesmo, para o muçulmano, ou seja, para uma vida nua não atribuível e não testemunhável. ${ }^{23}$

Esse processo de destituição do homem de sua humanidade torna-se característica decisiva da experiência política contemporânea. Nesta se expressa com certa acuidade o modo como a vida perde sua condição de limite, de limiar do poder soberano, e a vida nua se desnuda ainda mais; perde não apenas sua relação com a forma política, mas dela se aparta em definitivo: torna-se orgânica, perdendo até mesmo sua própria condição de vida animal. Em suma, a experiência do campo, ao fazer emergir na figura do muçulmano o paradigma político contemporâneo, põe em xeque doravante e progressivamente este limiar zoé-bíos, vida nua-forma de vida, corpo-sujeito jurídico, homem-cidadão. Segundo Agamben, "em Auschwitz, não se pode distinguir entre a morte e o simples desaparecimento, entre o morrer e o "ser liquidificado", 24 . E não mais como pena - e, ao mesmo tempo, como se todos de algum modo, nesta experiência, fossem culpados: a morte, o morrer, o afastar-se pouco a pouco da vida, da humanidade e até da existência tornam-se normal. O poder de morte se autoriza e se impõe sobre a vida. Mas uma vez citando a Levi, Agamben ressalta: "onde o pensamento da morte foi materialmente realizado, onde a morte 'era trivial, burocrática e cotidiana', tanto a morte como o morrer, tanto o morrer como os seus modos, tanto a morte como a fabricação de cadáveres se tornam indiscerníveis". ${ }^{25}$

E é nesta experiência que, segundo Agamben, constitui-se a indiscernibilidade entre o humano e o não-humano, justamente porque também se manifesta nela a indistinção entre vida e morte, da qual o muçulmano é a imagem. "De fato, em um caso, ele [o muçulmano] se apresenta como o não-vivo, como o ser cuja vida não é realmente vida; no outro, como aquele cuja morte não pode ser chamada de morte, mas apenas fabricação de cadáveres". ${ }^{26} \mathrm{O}$ poder que se manifesta aqui não pode mais assumir a forma simplesmente de um poder de vida ou de morte. Não se

Cadernos Benjaminianos, Número especial, Belo Horizonte, 2013, página 77-88 
manifesta mais o poder como a instância que faz morrer e deixa viver, como na experiência absolutista, ou como a instância que faz viver e deixa morrer, como no princípio moderno liberal. "O que é inumano é tal poder, tal quase infinita potência de sofrer - não os fatos, nem as ações ou as omissões". ${ }^{27}$ O inumano é sobre o que incide o poder, e ele mesmo, o poder, torna-se inumano, mas apenas e à medida que, como humano, mantém-se numa zona de absoluta indistinção com o inumano.

\section{O arcana imperii do biopoder contemporâneo}

Muito mais do que a inserção da vida nos cuidados e nos dispositivos do poder soberano, o que caracteriza o poder na contemporaneidade é a constituição dessa zona de indistinção entre norma e fato, entre vida e direito. E esta indistinção apresenta-se de modo mais decisivo justamente na experiência do campo de concentração, que, como tal, põe e faz surgir a própria indistinção entre humano e não-humano, entre vida e morte. Para além de sua tomada pela preocupação do poder e como objeto de providência, o que ocorre de modo particular à política contemporânea é

a inscrição na vida de uma zona morta e, na morte, de uma zona viva. Em ambos os casos - já que o homem assiste à destruição de seu vínculo privilegiado com o que o constitui como humano, a saber, com a sacralidade da morte e da vida -, o que está sendo posto em jogo é a própria humanidade do homem. ${ }^{28}$

Assim, a política da modernidade, à medida que se expressa como biopolítica e chega às suas últimas consequências com o campo, marca-se nos tempos contemporâneos pela destituição do humano de sua forma política, de sua dignidade, de sua humanidade, até mesmo de sua animalidade. Destitui-se o homem da "graça", desnuda-o e se o lança na terra de ninguém do estado de exceção: "espaço biopolítico absoluto, ao mesmo tempo Lebensraum e Todesraum [espaço de vida e espaço de morte], no qual a vida humana passa a estar além de qualquer identidade biopolítica atribuível. A morte é, nesse ponto, um simples epifenômeno" "29. A morte não se apresenta aqui como pena, tampouco como sacrifício. Ela ocupa aquele lugar de uma indiscernibilidade entre o sagrado e o profano, já que ela se dirige ao muçulmano, o homo sacer por excelência, e, como tal, afirma-se numa absoluta indistinção com a vida.

Para Agamben, no Estado nazista,

uma absolutização sem precedentes do biopoder de fazer viver se cruza com uma não menos absoluta generalização do poder soberano de fazer morrer, de tal forma que a biopolítica coincide imediatamente com a tanatologia. Essa coincidência representa, na perspectiva foucaultiana, um verdadeiro paradoxo que, conforme acontece com qualquer paradoxo, exige uma explicação. Como é possível que um poder cujo objetivo é essencialmente o de fazer viver exerça por sua vez um incondicionado poder de morte ? $^{30}$

A inquietação de Agamben passa a se conduzir então pela busca de desvendar o arcana imperii, o mistério do poder, ou melhor dizendo, do biopoder. $\mathrm{O}$ autor

Cadernos Benjaminianos, Número especial, Belo Horizonte, 2013, página 77-88 
italiano segue numa análise que visa identificar os elementos que tornam o poder, na contemporaneidade, ao mesmo tempo um poder sobre a vida, de modo a fazer com que ela se mantenha enquanto tal, e um poder sobre a morte, à medida que ele não se estabelece como aquele que institui a morte, mas como aquele cuja ação sobre a vida não pode se dissociar de sua ação sobre a morte. Se, para Foucault, na experiência absolutista manifesta-se o poder da "soberania com a fórmula fazer morrer e deixar viver", ${ }^{31}$ e na biopolítica liberal isto se converte em "fazer viver e deixar morrer", ${ }^{32}$ para Agamben, esta distinção se torna cada vez menos clara. Para este autor, o que está em jogo na biopolítica desde o século XX - e isto é absolutamente central à compreensão de que o muçulmano é a figura paradigmática do contemporâneo - já não é mais "fazer morrer nem fazer viver, mas fazer sobreviver". 33

Mas o que significa, sob o paradigma contemporâneo do muçulmano, sobreviver? Ou, ainda, qual a relação entre o muçulmano, tomado como paradigma político contemporâneo, e o sobrevivente, que passa a ser o produto da atual experiência política? Essas perguntas não encontram uma resposta imediata, mas podemos aproximar-nos dela considerando que a experiência do campo de concentração se apresenta de modo peculiar justamente porque lá "é o lugar em que realmente ninguém consegue morrer ou sobreviver no seu próprio lugar" ${ }^{34}$ E se o humano é o que sobrevive ao não-humano, assim como o não-humano sobrevive ao humano, poderíamos dizer que o campo de concentração é o marco a partir do qual a política é a experiência de produção de ambos, ou de sua indistinção, sendo por isso mesmo uma biopolítica produtora do sobrevivente. "Na biopolítica contemporânea, a sobrevivência é o ponto em que as duas faces coincidem, é o vir à luz do arcana imperii como tal. Por esse motivo, ele permanece, por assim dizer, invisível na sua própria exposição, ficando tanto mais recôndito quanto mais exposto ao olhar". ${ }^{35}$

Se o campo é o lugar em que a biopolítica moderna chega às suas últimas consequências, é na imagem do muçulmano que ela então encarna todo o seu significado: "No muçulmano, o biopoder pretendeu produzir o seu último arcano, uma sobrevivência separada de qualquer possibilidade de testemunho, uma espécie de substância biopolítica absoluta que, em seu isolamento, permite que se confira qualquer identidade demográfica, étnica, nacional e política". ${ }^{36}$ Daí que, para o pensador italiano, torna-se crucial a reflexão sobre essa experiência. Diz ele: os campos "não são apenas o lugar da morte e do extermínio, mas também, e antes de qualquer outra coisa, o lugar de produção do muçulmano, da última substância biopolítica isolável no continuum biológico". ${ }^{37}$ É o muçulmano esse limite ao qual a experiência biopolítica pôde (e pode!) chegar. E, nas análises de Agamben, a função do campo é muito mais que produzir um isolamento étnico, nacional etc., pois ele só o produz à medida que visa ir além dessa distinção entre nacionalidades, entre existências mediadas pelo nascimento, pela forma política da nacionalidade e por outras distinções que se queiram políticas. O que se realiza com esta experiência é a distinção de si mesmo no interior do próprio homem. "A ambição suprema do biopoder consiste em produzir em um corpo humano a separação absoluta entre o ser vivo e o ser que fala, entre zoé e o bíos, o não-homem e o homem: a sobrevivência". 38

A sobrevivência - à qual nos remete constantemente a figura do muçulmano e da qual só se pode falar a partir do paradigma deste - é, pois, esse limiar em que se coloca a relação entre a vida destituída de toda e qualquer forma e a forma de vida. Posta neste limbo, a ação do poder sobre o homem perde a relação direta com o direito enquanto forma da relação com o indivíduo mediada pela sua dignidade, já

Cadernos Benjaminianos, Número especial, Belo Horizonte, 2013, página 77-88 
que aqui ele não assume forma jurídica, forma política, não é digno. Perde também toda relação com o sagrado, já que eles ali não se apresentam como objeto de expiação, nem de sacrifício. O que se mostra na experiência do campo é a possibilidade da ultrapassagem do limite, não sem muitas consequências. Assim como o limite da vida é ultrapassado, aqui também o é o limite do próprio direito (e igualmente da religião). Ele se extrapola a si mesmo à medida que sua aplicação, como direito, interverte-se em uma sua não-aplicação. "Nem a vida nem a morte, mas a produção de uma sobrevivência modulável e virtualmente infinita constitui a tarefa decisiva do biopoder em nosso tempo". ${ }^{39}$ É este, para Agamben, o fenômeno do "aviltamento" (Entwürdigung), própria à situação do muçulmano no campo.

O arcana escondido, o mistério que acaba por se revelar como paradigma da experiência biopolítica não pode ser outro senão esta vida apartada de si mesma e desnudada não apenas de sua forma política, mas da própria vida animal, a indiscernível sobrevivência que não pode ser apresentada como vida, tampouco como não-vida. Segundo o pensador italiano, é "somente este limiar, que não é nem a simples vida natural, nem a vida social, mas a vida nua ou vida sacra [que] é o pressuposto sempre presente e operante da soberania". ${ }^{40}$ A soberania política em sua forma propriamente moderna encontra a ampliação de seu limite para além da vida animal. E é como tal que esta figura atualizada e extrapolada do homo sacer - o muçulmano - apresenta-se como o elemento político originário do poder na modernidade. Banimento da cidade, banimento da casa, banimento de si mesma: este é o ápice a que pode chegar as injunções do biopoder sobre a vida. O que ocorre nesta experiência é que a vida é capaz de ir para além de si mesma num processo de despolitização, desumanização, até mesmo desanimalização.

Summary: In Remnants of Auschwitz: The Witness and the Archive, Agamben conceives a new level of biopolitcs experience, in which the state of exception as the norm brings with itself the "Muslim" as an exemplary figure. What characterizes biopolitics in contemporaneity in Agamben is less the opposition, in the classic sense, between bare life and forms-of-life, or still the lack of distinction between them, proper to the modern. What the field reveals is that may be an even deeper split in the man: on this split, organic life is isolated from animal life, thereby producing a mere existence devoid of humanity. This is the figure of the "Muslim", in which appears the separation of the non-human in relation to the human. From the experience of the concentration camps (and extermination), biopower is able to overcome the limit of the animal life of man to produce this separation within the human life itself.

Keywords: sovereignty; field; muslim.

\section{Referências}

AGAMBEN, G. O que resta de Auschwitz. Homo sacer III. Trad. bras. Selvino J. Assmann. São Paulo: Boitempo, 2008.

ARRUDA, D. Do fim da experiência ao fim do jurídico: percurso de Giorgio Agamben (Tese de doutorado). Campinas, SP: UNICAMP, 2010.

Cadernos Benjaminianos, Número especial, Belo Horizonte, 2013, página 77-88 
FOUCAULT, Michel. Vigiar e Punir. História da violência nas prisões. $21^{\mathrm{a}}$ ed. Trad. bras. Raquel Ramalhete. Petrópolis (RJ): Editora Vozes, 1987.

FOUCAULT, Michel. História da sexualidade, I. - A vontade de saber. $18^{\mathrm{a}}$ ed. Trad. bras. Maria Thereza da Costa Albuquerque e J. A. Guilhon Albuquerque. Rio de Janeiro: Edições Graal, 1988.

KANTOROWICZ, E. H. Os dois corpos do rei. Um estudo sobre a teologia política medieval. Trad. bras. Cid Knipel Moreira. São Paulo: Companhia das Letras, 1998.

LEVI, P. É isto um homem? Trad. bras. Luigi del Re. Rio de Janeiro: Rocco, 1988.

LEVI, P. Os afogados e os sobreviventes. Trad. bras. Luiz Sérgio Henriques. São Paulo: Paz e Terra, 2004.

PICO DELlA MIRANDOLA, Giovanni. Discurso sobre a dignidade do homem. Trad. port. de Maria de Lurdes Sirgado Ganho. Lisboa: Edições 70, 2001.

\section{Notas}

${ }^{1}$ AGAMBEN. O que resta de Auschwitz, p. 62. Segundo Primo Levi, por muçulmanos, "os veteranos do campo designavam os fracos, os ineptos, os destinados à 'seleção". Segundo ele próprio os descreve, eles "simplesmente, acompanharam a descida até o fim, [...] foram esmagados antes de conseguir adaptar-se [...]". São os "não-homens que marcham e se esforçam em silêncio; já se apagou neles a centelha divina, já estão tão vazios, que nem podem realmente sofrer. Hesita-se em chamá-los vivos; hesita-se em chamar 'morte' à sua morte, que eles já nem temem, porque estão esgotados demais para poder compreendê-la" (LEVI. É isto um homem? p. 89-91). Segundo Levi, a expressão Muselmann era comumente utilizada nos diversos campos, tendo sido, de acordo com Agamben, utilizada pela primeira vez no campo de Auschwitz. Essa expressão aparecia associada à figura daquele "prisioneiro irreversivelmente exausto, extenuado, próximo à morte" (LEVI. Os afogados e os sobreviventes, 2004, p. 85). Essa associação à figura do muçulmano, segundo ainda Levi, deu-se talvez por conta do uso de faixas na cabeça por esses homens, o que recordava o turbante; mas também pelo fatalismo que parecia marcar aquelas vidas. Ao refletir sobre essa expressão, Agamben destaca que, provavelmente, seu uso tenha relação com seu significado literal mesmo: aquele que "se submete incondicionalmente à vontade de Deus". (AGAMBEN, O que resta de Auschwitz, p. 52). Agamben se refere ao suposto fatalismo, como um significado de certo modo "depreciativo", advindo das culturas europeias desde o período medieval acerca dos islâmicos. Mas, a despeito dos sentidos e significados, dos quais aqui citamos apenas alguns, o que me parece destacar-se na descrição de Agamben, alinhada à de Levi, é o aspecto de limite a que chegam os denominados de muçulmanos: uma ida ao extremo, a chegada do homem no lugar da não-humanidade, a perda de sentido, de vontade, de sentimento. "Ou como figura nosográfica [em referência à certa enfermidade particular nos campos], ou como cartografia ética, ou alternadamente como limite político e conceito antropológico, o muçulmano é um ser indefinido, no qual não só a humanidade e a não humanidade, mas também a vida vegetativa e a de relação, a fisiologia e a ética, a medicina e a política, a vida e a morte transitam entre si sem solução de continuidade. Por isso, o seu 'terceiro reino' é a cifra perfeita do campo, do não-lugar onde todas as barreiras disciplinares acabam ruindo, todas as margens transbordam." (AGAMBEN. $O$ que resta de Auschwitz, p. 56). Para uma compreensão ainda mais aprofundada acerca da

Cadernos Benjaminianos, Número especial, Belo Horizonte, 2013, página 77-88 
exposição do muçulmano, conferir capítulo 9 de É isto um homem? e o capítulo 2 de AGAMBEN. O que resta de Auschwitz.

${ }^{2}$ Em Foucault, o que caracteriza o biopoder na modernidade é justamente a vida posta como limite, ou melhor dizendo, o cuidado como o corpo, expressão material da vida, é o que marca as estratégias do poder. Neste sentido, a mudança da forma de punição na passagem do século XVIII para o XIX, vai ocorrer justamente considerando a necessidade de preservação do corpo, da vida, do homem, de sua humanidade. Mesmo "no pior dos assassinos, uma coisa pelo menos deve ser respeitada quando punimos: sua humanidade" (FOUCAULT. Vigiar e punir, p. 63). O conceito de humanidade é, pois, para Foucault. O conceito limite do poder. Se o que caracterizava o poder soberano, no seu sentido mais amplo, era seu poder de morte, na modernidade este poder encontra seu limite: a própria vida que deve ser mantida por esse poder. É este conceito limite que aqui, como pretendo demonstrar, é posto em xeque pela experiência do campo.

3 AGAMBEN. O que resta de Auschwitz, p. 62.

${ }^{4}$ AGAMBEN. O que resta de Auschwitz.

5 AGAMBEN. O que resta de Auschwitz, p. 90. Como o descreve ainda Jeanne-Marie Gagnebin, "o 'muçulmano é o preso sem rosto que abdicou da luta, que não pode mais ser chamado de vivo nem de ter uma morte que mereceria esse nome. Figura de extrema desfiguração, o 'muçulmano' é o não-homem que habita e ameaça todo ser humano, a redução sinistra da vida à vida nua. [...] sua mera existência ameaça mossas representações mínimas do humano" (GAGNEBIN. Apresentação, p. 13-14).

${ }^{6}$ AGAMBEN. O que resta de Auschwitz.

${ }^{7}$ AGAMBEN. O que resta de Auschwitz, p. 152.

${ }^{8}$ AGAMBEN. O que resta de Auschwitz, p. 66.

${ }^{9}$ AGAMBEN. O que resta de Auschwitz, p. 69-70.

${ }^{10}$ AGAMBEN. O que resta de Auschwitz, p. 67.

${ }^{11}$ AGAMBEN. O que resta de Auschwitz, p. 87.

${ }_{12}$ AGAMBEN. O que resta de Auschwitz.

${ }_{13}^{13}$ AGAMBEN. O que resta de Auschwitz, p. 152.

${ }^{14}$ AGAMBEN. O que resta de Auschwitz, p. 70.

${ }_{15}$ AGAMBEN. O que resta de Auschwitz, p. 73.

${ }^{16}$ Cf. KANTOROWICZ, E. H. Os dois corpos do rei. Um estudo sobre a teologia política medieval.

${ }_{17}^{17}$ AGAMBEN. O que resta de Auschwitz, p. 73.

${ }^{18}$ AGAMBEN. O que resta de Auschwitz.

${ }^{19}$ PICO DELLA MIRANDOLA. Discurso sobre a dignidade do homem, p. 53.

20 AGAMBEN. O que resta de Auschwitz, p. 76. "Com o ingresso do conceito de dignidade na moral, e após as revoluções republicanas e democráticas, a sua comunicação à condição de todo ser humano veio mostrar como entre a vida do homem e a norma havia uma relação seminal. A dignidade é assim reconhecida como humana, como pertencente à humanidade. Mas a modernidade é também o ambiente em que vimos findar toda adequação entre vida e norma. Se a vida no campo de concentração pode ser vista como a plena realização da união entre vida e direito, em que decidir pelo segundo significa decidir pela primeira, o seu habitante natural, o muçulmano, é o testemunho de uma forma de vida que começa onde termina toda dignidade, vale dizer, toda relação com o direito". (ARRUDA. Do fim da experiência ao fim do jurídico: percurso de Giorgio Agamben, p. 99).

${ }^{21}$ Cf. FOUCAULT. História da sexualidade I - A vontade de saber.

${ }^{22}$ AGAMBEN. O que resta de Auschwitz, p. 78.

${ }_{23}^{23}$ AGAMBEN. O que resta de Auschwitz, p. 156.

${ }^{24}$ AGAMBEN. O que resta de Auschwitz, p. 82.

${ }^{25}$ AGAMBEN. O que resta de Auschwitz.

Cadernos Benjaminianos, Número especial, Belo Horizonte, 2013, página 77-88 
${ }^{26}$ AGAMBEN. O que resta de Auschwitz, p. 87.

${ }^{27}$ AGAMBEN. O que resta de Auschwitz, p. 83.

${ }^{28}$ AGAMBEN. O que resta de Auschwitz, p. 87.

${ }^{29}$ AGAMBEN. O que resta de Auschwitz, p. 91.

${ }^{30}$ AGAMBEN. O que resta de Auschwitz, p. 89.

${ }_{31}$ AGAMBEN. O que resta de Auschwitz. O que resta de Auschwitz, p. 88.

${ }^{32}$ AGAMBEN. O que resta de Auschwitz.

${ }^{33}$ AGAMBEN. O que resta de Auschwitz, p. 155.

${ }^{34}$ AGAMBEN. O que resta de Auschwitz, p. 108.

${ }^{35}$ AGAMBEN. O que resta de Auschwitz, p. 156. "No seu De arcanis rerum publicarum (1605), Clapmar distinguia, na estrutura do poder, uma face visível (o jus imperii) e uma face oculta (o arcanum, que ele deriva de arca, cofre, caixa de ferro)". Para Agamben, é na experiência da biopolítica contemporânea, sobretudo na imagem do sobrevivente, que esta face oculta é desvelada, e justamente à medida que ela se torna coincidente com a face visível. Exatamente por isso, por coincidirem o jus imperii e o arcanum, o segundo, em sua exposição, é camuflado.

${ }^{36}$ AGAMBEN. O que resta de Auschwitz.

${ }^{37}$ AGAMBEN. O que resta de Auschwitz, p. 90.

${ }^{38}$ AGAMBEN. O que resta de Auschwitz, p. 156.

${ }^{39}$ AGAMBEN. O que resta de Auschwitz, p. 155-156.

${ }^{40}$ AGAMBEN. O que resta de Auschwitz, p. 113. 